\title{
Contribution of Facet Joints to Chronic Low Back Pain in Postlumbar Laminectomy Syndrome: A Controlled Comparative Prevalence Evaluation
}

\author{
Laxmaiah Manchikanti, MD*, Vidyasagar Pampati, M Sc**, A. Ghafoor Baha, MD ${ }^{\Omega}$, Bert Fellows, MA*, \\ Kim S.Damron, RN" and Renee C. Barnhill, RN
}

Postlumbar laminectomy syndrome, or pain following operative procedures of the lumbar spine, is increasingly a common entity in modern medicine. Multiple causes proposed for recurrence of pain after lumbar laminectomy are: epidural fibrosis, recurrent disc herniation, instability, and facet joints. Even though the prevalence of persistent low back pain secondary to the involvement of lumbosacral facet joints has been described in controlled studies from $15 \%$ to $45 \%$, the prevalence of facet joint mediated pain in postlumbar laminectomy syndrome has not been studied. This prospective, randomized, controlled comparative evaluation was performed to determine the prevalence of facet joint mediated pain in persistent low back pain in postlumbar laminectomy patients with a comparative non-surgical group.

One hundred patients with fifty patients in each group were randomly assigned with group I consisting of fifty patients without history of previous surgery and group II consisting of fifty patients with history of previous surgery.

Results showed that the prevalence of facet joint mediated pain in non-surgical patients was $44 \%$ compared to $32 \%$ in post surgical patients determined by comparative controlled local anesthetic blocks utilizing lidocaine and bupivacaine. This study also showed a false positive rate of $36 \%$ in nonsurgical group and $24 \%$ in post-surgical group. In conclusion, this study shows that facet joint mediated symptomatology in chronic low back pain is prevalent, both in nonsurgical as well as post-surgical patients even though prevalence was somewhat higher in the non-surgical group compared to post-surgical group.

Keywords: Chronic low back pain, facet joint mediated pain, facet joint injections, controlled diagnostic blocks, postlumbar laminectomy syndrome
Postlumbar laminectomy syndrome or pain following operative procedures of the lumbar spine is becoming a common entity in modern medicine $(1,2)$. Although the exact incidence and prevalence of postlumbar laminectomy syndrome is not known, it is estimated that $20 \%$ to $30 \%$ of lumbar spinal surgeries (occasionally as high as $40 \%$ ), may not be successful as a result of either the surgery being inadequate, incorrect or unnecessary. Unfortunately, poor outcomes may also result following a well indicated and well performed surgical procedure. Waddell et al (3) noted that in all studies of back pain, $10 \%$ to $15 \%$ of patients account for $80 \%$ to $90 \%$ of the total health care compensation and cost for spinal disorders, and the $1 \%$ to $2 \%$ of

From Pain Management Center of Paducah, Paducah, Kentucky. *Medical Director, **statistician, ${ }^{\Omega}$ interv-entional

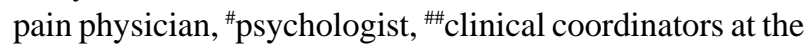
Pain Management Center of Paducah. Address correspondence: Laxmaiah Manchikanti, MD, 2831 Lone Oak Road, Paducah, KY 42003. E-mail: drm@ asipp.org. patients who undergo surgery are the most expensive group. Fritsch et al (4) reported that, in $80 \%$ of the patients, results were satisfactory in short-term evaluation, decreasing to $22 \%$ in long-term follow-up after lumbar surgical intervention. Epidural fibrosis, recurrent disc herniation, instability, and facet joints have been implicated for recurring symptomatology. Even though the prevalence of persistent low back pain secondary to the involvement of lumbosacral facet joints has been described in controlled studies variably from $15 \%$ to $45 \%$ (5-10), the prevalence of facet joint mediated pain in postlumbar laminectomy syndrome has not been determined. Some controlled evaluations of prevalence of facet joint mediated pain in persistent low back pain (8-10) have consistently shown the lower prevalence of facet joint mediated pain in postlumbar laminectomy pain patients and negative correlation of history of previous surgery with diagnosis of facet joint mediated pain.

Since there have not been any controlled prevalence evaluations of facet joint mediated pain in postlumbar laminec- 
tomy syndrome, this study was undertaken to evaluate the prevalence of facet joint mediated pain in persistent low back pain in postlumbar laminectomy patients with a comparative non-surgical group.

\section{METHODS}

This study included one hundred patients randomly allocated with fifty patients in each group. Group I consisted of fifty patients without history of previous surgery, whereas group II consisted of fifty patients with history of previous surgery. Of all the patients presenting for pain management to one private interventional pain management practice with a chief complaint of low back pain, with or without lower extremity pain, one hundred of these patients were randomly allocated to one physician. Patients who exhibited neurological deficits, patients younger than 18 years or older than 90 years, patients who had pain for less than six months, those who had responded to conservative management, and those who had undergone blockade in the past with facet joint nerve blocks or intraarticular injections were excluded. All the patients were explained the nature of the study, as well as potential hazards of the procedures. All of them understood and consented to participate. Facet joints were investigated with diagnostic blocks using lidocaine $1 \%$, initially followed by bupivacaine $0.25 \%$, usually two weeks apart. Evaluation included completion of a standard pain management questionnaire, history, physical examination, and evaluation of the results of all procedures and investigations. The blocks were performed in an operating room by one investigator under fluoroscopic visualization, with the patient in a prone position. All the patients received mild sedation with midazolam. Facet joint nerve blocks were performed under intermittent fluoroscopic visualization, at each of the medial branches at L1 through L4 and L5 dorsal ramus, using a 22-gauge, 3.5-inch spinal needle. Infiltration of each nerve was carried out with 0.4 to $0.6 \mathrm{~mL}$ of either $1 \%$ lidocaine or $0.25 \%$ bupivacaine with or without adjuvants. A definite response was defined as relief of at least $75 \%$ in the symptomatic area. Following each block, the patient was examined and painful movements and maneuvers were performed. Confirmatory blocks using bupivacaine $0.25 \%$ were performed at the same levels as the first injection, only if definite relief was obtained. The response to bupivacaine blocks was evaluated after at least two weeks following the second injection, with pain relief lasting longer than the duration of the lidocaine blocks for at least three hours. Any other response was considered as negative.
Data was recorded on a database using Microsoft Access. The SPSS Version 9.0 statistical package was used to generate the frequency tables and the chi-squared statistic was used to test the significance difference between groups. Student's t test was used to test mean difference between groups. Results were considered statistically significant if the $P$ value was less than 0.05 .

\section{RESULTS}

\section{Patient Characteristics}

Salient characteristics of the patients with gender, age, weight, height, body mass index, mode of onset of pain, duration of pain and pain ratio are shown in Table 1. Significant differences were noted only with duration of pain among the groups with a greater number of patients in group II experiencing pain for longer than four years. In addition, mode of onset of pain also showed that gradual onset was higher in non-surgical group (group I) with 60\%, whereas in post-surgical group (group II) it was only $32 \%$.

\section{Injection Characteristics}

All patients underwent single blocks with lidocaine, with or without adjuvants. Thirty two or $64 \%$ of the patients in group I, twenty four or $48 \%$ of the patients in group II, reported a definite response to screening blocks with lidocaine. Confirmatory blocks with bupivacaine were performed in all patients who were lidocaine-positive, with $44 \%$ of the total sample or $69 \%$ of the lidocaine-positive group reporting a definite response with improvement in pain in group I, in contrast with $32 \%$ of the total sample or $67 \%$ of the lidocaine-positive in group II (Table 2).

\section{Prevalence}

All the patients who underwent double blocks with a definite response were considered as positive, yielding a prevalence rate of facet joint pain in chronic low back pain in the non-surgical group of $44 \%$, and in the post-surgical group of $32 \%$. However, there were no significant differences noted among the groups with regards to prevalence of facet joint mediated chronic low back pain.

\section{Specificity}

The specificity was calculated by determining the proportion of patients who had no response to lidocaine. Using the response to double blocks as a criterion standard, the 
Table 1: Patient Characteristics

\begin{tabular}{|c|c|c|c|}
\hline & & $\begin{array}{c}\text { Group I } \\
\text { (Non-surgical) }\end{array}$ & $\begin{array}{c}\text { Group II } \\
\text { (Post-surgical) }\end{array}$ \\
\hline Number of patients & & $\mathrm{N}=50$ & $\mathrm{~N}=50$ \\
\hline \multirow{2}{*}{ Gender } & Male & $40 \%(20)$ & $52 \%(26)$ \\
\hline & Female & $60 \%(30$ & $48 \%(24)$ \\
\hline \multirow{2}{*}{ Age (yrs.) } & Range & $22-82$ & $32-85$ \\
\hline & Mean \pm SEM & $46.9 \pm 2.22$ & $48.5 \pm 1.92$ \\
\hline \multirow{2}{*}{ Weight (lbs.) } & Range & $116-302$ & $104-304$ \\
\hline & Mean \pm SEM & $183 \pm 6.9$ & $187 \pm 7.03$ \\
\hline \multirow{2}{*}{ Height (inches) } & Range & $60-75$ & $59-77$ \\
\hline & Mean \pm SEM & $67.1 \pm 0.57$ & $67.7 \pm 0.56$ \\
\hline Body Mass Index & Mean \pm SEM & $28.4 \pm 0.92$ & $28.6 \pm 0.99$ \\
\hline \multirow{4}{*}{ Mode of Onset of pain } & Occupational & $10 \%(5)$ & $46 \%(23)$ \\
\hline & Motor vehicle accident & $16 \%(8)$ & $8 \%(4)$ \\
\hline & Non-Occupational incident & $14 \%(7)$ & $14 \%(7)$ \\
\hline & Gradual onset & $60 \% *(30)$ & $32 \%(16)$ \\
\hline \multirow{4}{*}{ Duration of pain (years.) } & Range & $0.5-25$ & $0.5-25$ \\
\hline & $\leq 1$ & $22 \%(11)$ & $6 \%(3)$ \\
\hline & $1-4$ & $32 \%(16)$ & $24 \%$ \\
\hline & $>4$ & $46 \%(23)$ & $70 \% *(35)$ \\
\hline \multirow{4}{*}{ Pain Ratio } & Back pain only & $16 \%(8)$ & $2 \%(1)$ \\
\hline & Back worse than leg & $48 \%(24)$ & $44 \%(22)$ \\
\hline & Back \& leg pain equal & $22 \%$ & $32 \%(16)$ \\
\hline & Leg pain worse than back & $14 \%(7)$ & $22 \%$ \\
\hline
\end{tabular}

* Indicates significant difference ( ) Number of patients

specificity of lidocaine was found, on average, to be only $64 \%$, with a resultant false positive rate of $36 \%$ in nonsurgical group, group I, whereas specificity was $76 \%$ in post-surgical or group II with a false positive rate of $24 \%$.

\section{DISCUSSION}

There is a preponderance of evidence supporting the existence of lumbar facet joint pain $(1,5-26)$. The rationale for diagnosis of facet joint mediated pain utilizing controlled blocks is based on the observation that if a particular joint is determined to be the source of pain generation, long-term relief can be sought by directing therapeutic interventions at that joint $(1,5-11,24,26)$. Facet joint mediated pain may be diagnosed by either placebo controlled diagnostic facet joint blocks or comparative local anesthetic blocks, in which on two separate occasions, the same structure is anesthetized, but using local anesthetic with different durations of action. Controlled comparative local anesthetic blocks are implemented readily for medial branch blocks. With medial branch blocks, the use of comparative local anesthetic blocks has been evaluated and found to be valid against challenge with placebo (1, 26). 
Table 2. Comparison of the results of single blocks (lidocaine) and double blocks (lidocaine and bupivacaine)

\begin{tabular}{|c|c|c|c|c|}
\hline \multirow[b]{3}{*}{ Single block } & \multicolumn{2}{|c|}{ Non-surgical $(\mathrm{N}=50)$} & \multicolumn{2}{|c|}{ Post-surgical $(\mathrm{N}=50)$} \\
\hline & \multicolumn{2}{|c|}{ Double blocks } & \multicolumn{2}{|c|}{ Double blocks } \\
\hline & Positive & Negative & Positive & Negative \\
\hline Positive & 22 & 10 & 16 & 8 \\
\hline Negative & & 18 & & 26 \\
\hline Prevalence & \multicolumn{2}{|c|}{$44 \%$} & \multicolumn{2}{|c|}{$32 \%$} \\
\hline False positive rate & \multicolumn{2}{|c|}{$36 \%$} & \multicolumn{2}{|c|}{$24 \%$} \\
\hline Specificity & \multicolumn{2}{|c|}{$64 \%$} & \multicolumn{2}{|c|}{$76 \%$} \\
\hline
\end{tabular}

Even though the exact incidence and prevalence of postlumbar laminectomy syndrome is unknown, the estimations of prevalence of recurrent pain after spinal surgeries run from $20 \%$ to $30 \%$, occasionally as high as $40 \%$ to $50 \%$. Fritsch et al (4) reported that results were satisfactory in short-term evaluation in $80 \%$ of the patients, with satisfactory results in only $22 \%$ of the patients in longterm follow-up evaluation after lumbar cervical intervention. Fager and Freidberg (27) following the analysis of failures of lumbar surgery, concluded that $51 \%$ of the patients had more than one operation; among them $11 \%$ improved, 34\% did not change, and 55\% worsened. They also showed that only $32 \%$ improved following initial operation, but the improvement was short-lived, with 6 months or less in 50\% of the patients. Surprisingly in 1951, Barr (28) reported that a patient may have persistent low back pain, sciatica, or both, in spite of surgical intervention. Berger and Davies (29), recently after evaluating 1000 patients undergoing surgical interventions with 600 patients undergoing a single operation, reported that only $17 \%$ of the patients consider themselves improved, whereas $32 \%$ remained unchanged, with a significant number of patients $(51 \%)$ reporting that they were worse than prior to surgery. Tissues in the lower back capable of transmitting pain include muscles, ligaments, fascia, discs, nerve root dura, and facet joints (30). It is postulated that spinal pain commonly originates from several compartments, since the intricacy of the functional spine, often fails in more than 1 of its parts at the same time. Kirkaldy-Willis et al (31) described the pathogenesis of degenerative cascade in the context of a 3-joint complex that involves the articulation between 2 vertebrae, consisting of the intravertebral disc and adjacent facet joints, as changes within each member of this joint complex will result in changes in others. Thus, failed back surgery syndrome is no exception. While epidural fibrosis and instability may be responsible for the majority of the recurrent pain after failed surgical interventions, facet joints also contribute to significant causes of persistent low back pain. In addition, the facet joint plays a significant role in the structural degenerative cascade. Following the surgical intervention degenerative disc disease is often seen with the loss of disc volume leading to closure of the intravertebral foramen by movement of the superior articular facet. This further may lead to a loss of dynamic integrity leading to segmental instability and abnormal motion as well as facet hypertrophy and strain resulting in facet joint mediated pain.

This study showed prevalence of facet joint mediated pain in postlumbar laminectomy patients as $32 \%$ compared to $44 \%$ of the patients in group I who never underwent any surgical procedures on the lumbar spine. The results are similar to various controlled studies in the past. The criteria adapted for the diagnosis of lumbar facet joint pain in this study are as stringent as those adapted by the previous studies. However, this study is the first to assess the prevalence of facet joint pain in a heterogeneous group of populations suffering with chronic low back pain in the United States in a multidisciplinary, private interventional pain management practice in a non-university setting, involving two groups of patients distinctly separated by surgical intervention. This study demonstrates definite prevalence of definite involvement of facet joints in causing persistent low back pain in patients after undergoing surgical interventions. The false-positive rates of blocks of $24 \%$ in postlumbar laminectomy surgery patients and $36 \%$ in nonsurgical patients are similar to previous reports of $25 \%$ to $41 \%$. 
This study may be criticized by groups who do not believe in the existence of facet joint pain or those who believe only in the discogenic origin of pain or epidural fibrosis. However, the evidence showing the existence of facet joint mediated pain is not only extensive but also convincing. However, often facet joints as a source of low back pain are ignored $(2,32)$.

In summary, while this study echoes previous concerns of reliability of uncontrolled single blocks, and reliability of studies performed specifically in selected groups of patients with suspected facet joint pain, this study also demonstrates significant incidence of facet joint mediated pain in postlumbar laminectomy syndrome which often is ignored in favor of discogenic etiology or epidural fibrosis and instability. This study demonstrated that the facet joints are a resource of pain in $32 \%$ of the patients who had undergone surgical interventions on the lumbar spine. However, the incidence of facet joint mediated pain and postlumbar laminectomy syndrome is lower than in a comparative group of patients who never underwent surgical procedures on the lumbar spine.

\section{CONCLUSION}

The results of this study echo previous concerns of reliability of uncontrolled single blocks, along with history and clinical features. However, this study demonstrated that the facet joint is a source of pain in a significant number of patients with a prevalence of $44 \%$ in patients who never underwent surgery compared to $32 \%$ in the patients who underwent surgical intervention.

\section{ACKNOWLEDGMENTS}

We would like to thank Marla K. Neihoff and Lori A. Rose, medical records coordinators, for their assistance in collection of data. We would also like to thank Denise Pratt and Tonie Hatton, transcriptionists, for their assistance with transcription of the manuscript.

\section{REFERENCES}

1. Manchikanti L, Singh V, Kloth D et al. Interventional techniques in the management of chronic pain: Part 2.0. Pain Physician 2001; 4(1)24-96.

2. Wilkinson HA. The role of improper surgery in the etiology of the failed back syndrome. In: The Failed Back Syndrome. Etiology and therapy, Second Edition. Springer-Verlag, New York, 1992, pp 4-12.

3. Waddell G, Gibson NA, Grant I. Surgical treatment of lumbar disc prolapse and degenerative lumbar disc disease. In Nachemson AL, Jonsson E (eds). Neck and Back Pain. Lippincott Williams \& Wilkins, Philadelphia, 2000, pp 305-325.

4. Fritsch EW, Heisel J, Rupp S. The failed back surgery syndrome. Reasons, intraoperative findings, and longterm results: A report of 182 operative treatments. Spine 1996; 21:626-633.

5. Schwarzer AC, Aprill CN, Derby R et al. Clinical features of patients with pain stemming from the lumbar zygapophysial joints. Is the lumbar facet syndrome a clinical entity? Spine 1994; 19:1132-1137.

6. Schwarzer AC, Wang S, Bogduk N et al. Prevalence and clinical features of lumbar zygapophysial joint pain: A study in an Australian population with chronic low back pain. Am Rheum Dis 1995; 54:100-106.

7. Schwarzer AC, Aprill CN, Derby R et al. The relative contributions of the disc and zygapophyseal joint in chronic low back pain. Spine 1994; 19:801-806.

8. Manchikanti L, Pampati VS, Fellows B et al. Prevalence of lumbar facet joint pain in chronic low back pain. Pain Physician 1999; 2:59-64.

9. Manchikanti L, Pampati VS, Bakhit CE et al. The diagnostic validity and therapeutic value of lumbar facet joint nerve blocks with or without adjuvant agents. Cur Rev Pain 2000; 4:337-344.

10. Manchikanti L, Pampati V, Fellows B et al. The inability of the clinical picture to characterize pain from facet joints. Pain Physician 2000; 3:158-166.

11. Manchikanti L. Facet joint pain and the role of neural blockade in its management. Cur Rev Pain 1999; 3:348-358.

12. McCall IW, Park WM, O'Brien JP. Induced pain referral from posterior elements in normal subjects. Spine 1979; 4:441-446.

13. Marks R. Distribution of pain provoked from lumbar facet joints and related structures during diagnostic spinal infiltration. Pain 1989; 39:37-40.

14. Fukui S, Ohseto K, Shiotani M et al. Distribution of referral pain from the lumbar zygapophyseal joints and dorsal rami. Clin J Pain 1997; 13:303-307.

15. Schwarzer AC, Derby R, Aprill CN et al. The value of the provocation response in lumbar zygapophysial joint injections. Clin J Pain 1994; 10:309-313.

16. Schwarzer AC, Wang S, Laurent $\mathrm{R}$ et al. The role of the zygapophysial joint in chronic low back pain. Aust N Z J Med 1992; 22:185.

17. Schwarzer AC, Derby R, Aprill CN et al. Pain from the lumbar zygapophysial joints: A test of two models. J Spinal Disord 1994; 7:331-336.

18. Carette S, Marcoux S, Truchon R et al. A controlled trial of corticosteroid injections into facet joints for chronic low back pain. NEngl J Med 1991; 325:10021007.

19. Desoutet JM, Gilula LA, Murphy WA et al. Lumbar facet joint injection: Indication, technique, clinical correlation, and preliminary results. Radiology 1982; 145:321-325. 
20. Lippitt AB. The facet joint and its role in spine pain. Management with facet joint injections. Spine 1984; 9:746-750.

21. Lewinnek GE, Warfield CA. Facet joint degeneration as a cause of low back pain. Clin Orthop 1986; 213:216-222.

22. Lilius G, Laasonen EM, Myllynen P et al. Lumbar facet joint syndrome. A randomized clinical trial. $J$ Bone Joint Surg (Br) 1989; 71:681-684.

23. Lynch MC, Taylor JF. Facet joint injection for low back pain. A clinical study. J Bone Joint Surg (Br) 1986; 68:138-141.

24. Manchikanti L, Pampati V, Bakhit CE et al. Effectiveness of lumbar facet joint nerve blocks in chronic low back pain: A randomized clinical trial. Pain Physician 2001; 4:101-117.

25. Kaplan M, Dreyfus P, Halbrook B et al. The ability of lumbar medial branch blocks to anesthetize zygapophysial joint. Spine 1998; 23:1847-1852.

26. Bogduk N. International Spinal Injection Society guidelines for the performance of spinal injection procedures. Part 1: Zygapophyseal joint blocks. Clin $J$
Pain 1997; 13:285-302.

27. Fager CA, Freidberg, SR. Analysis of failures and poor results of lumbar spine surgery. Spine 1980; 5:432436.

28. Barr JS. Low back pain and sciatic pain. J Bone Joint Surg 1951; 33:633-649.

29. Berger E, Davis JMB. Chronic pain following lumbar spinal surgery in 1000 patients. Proceedings of $9^{\text {th }}$ World Congress on Pain, August 1999, pp181-182.

30. Kuslich SD, Ulstrom CL, Michael CJ. The tissue origin of low back pain and sciatica: A report of pain response to tissue stimulation during operation on the lumbar spine using local anesthesia. Orthop Clin North Am 1991; 22:181-187.

31. Kirkaldy-Willis WH, Wedge JH, Yong-Hing K et al. Pathology and pathogenesis of lumbar spondylosis and stenosis. Spine 1978;3:319-327.

32. Fanciullo GJ, Hanscom B, Seville J et al. An observational study of the frequency and pattern of use of epidural steroid injection in 25,479 patients with spinal and radicular pain. Reg Anesth Pain Med 2001; 26: 511. 